\title{
A STUDY ON COMPARATIVE YIELDS OF STANDARD SHORT TERM ELECTROENCEPHALOGRAM AND LONG TERM ELECTROENCEPHALOGRAM RECORDING IN SUSPECTED EPILEPSY PATIENTS
}

\author{
Saima Shafait, Wasim Alamgir, Imran Ahmad, Saeed Arif, Jahanzab Liaqat, Asif Hashmat \\ Pak Emirates Military Hospital/National University of Medical Sciences (NUMS) Rawalpindi Pakistan
}

\begin{abstract}
Objective: To compare the yield of interictal epileptiform discharges on prolonged (1-2 hours) electroencephalogram (EEG) as compared to standard routine (30 minutes) electroencephalogram (EEG).

Study Design: Comparative observational study.

Place and Duration of Study: Pak Emirates Military Hospital, Rawalpindi from Oct 2019 to Sep 2020.

Methodology: A total of 364 outdoor patients with suspected epilepsy were recruited for the study. Out of these 55 electroencephalograms were excluded after applying exclusion criteria and 309 were included for final analysis. Electro-encephalograms were recorded using a 10-20 international system of electrode placement. The duration of each standard electroencephalogram was 30 minutes. It was followed by recording for an extended period of 60 minutes at least. The time to the appearance of the first abnormal interictal epileptiform discharge was noted. For analytical purposes, epileptiform discharges were classified as "early" if they appeared within the first 30 minutes and as "late" if appeared afterward. All electro-encephalograms were evaluated independently by two neurologists.

Results: A total of 309 electroencephalograms were included for final analysis. Interictal epileptiform discharges were seen in $48(15.6 \%)$ recordings. The mean time to appearance of first interictal epileptiform discharge was $14.6 \pm 19.09$ minutes. In $36(11.7 \%)$ cases, discharges appeared early (within the first 30 minutes) whereas in the remaining $12(3.9 \%)$ cases, discharges appeared late. This translates into a $33 \%$ increase in the diagnostic yield of electroencephalogram with an extended period of recording.

Conclusion: Extending the electroencephalogram recording time results in a significantly better diagnostic yield of outdoor electroencephalogram.
\end{abstract}

Keywords: Electroencephalogram, Epilepsy, Interictal epileptiform discharge.

How to Cite This Article: Shafait S, Alamgir W, Ahmad I, Arif S, Liaqat J, Hashmat A. A Study on Comparative Yields of Standard Short-Term Electroencephalogram and Long-Term Electroencephalogram Recording in Suspected Epilepsy Patients. Pak Armed Forces Med J 2021; 71(5): $1727-1731$. doi: https://doi.org/10.51253/pafmj.v71i5.5921

This is an Open Access article distributed under the terms of the Creative Commons Attribution License (https://creativecommons.org/licenses/by-nc/4.0/), which permits unrestricted use, distribution, and reproduction in any medium, provided the original work is properly cited.

\section{INTRODUCTION}

Epilepsy is a disease characterized by an enduring predisposition to generate epileptic seizures and by the neurobiological, cognitive, psychological, and social consequences of this condition. Epilepsy has gruesome physical and psychological impact not only on the affected person but also on the whole family. According to WHO, 50 million people are affected worldwide ${ }^{1}$. Pooled lifetime prevalence of epilepsy is 7.60 per 1000 persons whereas annual cumulative incidence is 67.77 per 100,000 persons according to a metaanalysis done by Fiest et al. ${ }^{1}$ Close to $80 \%$ of the affected population lives in low to middle income countries where a large treatment gap exists due to lack of integrated healthcare services and inadequate resources. Reasons can be higher antenatal and perinatal risk, higher rates of CNS infections and traumatic brain

Correspondence: Dr Saima Shafait, Resident Medical Officer, Pak Emirates Military Hospital, Rawalpindi Pakistan

Received: 28 Dec 2020; revision received: 25 Jan 2021; accepted: 18 Feb 2021 injuries in lower socioeconomic groups. More than 13 million DALY (Disability adjusted life years) have been attributed to epilepsy in the year 2016 only. ${ }^{2}$ The success of reducing the burden of epilepsy depends on accessibility to healthcare, prompt diagnosis and treatment.

Electroencephalography (EEG) is a short sample of brain activity that is used to record cerebral activity in real time and is a major, noninvasive investigation for diagnosis and management of epilepsy. ${ }^{3}$ Minimal technical requirements have been advised by different societies on the basis of best available evidence. As far as duration is concerned, American Clinical Neurophysiology Society recommends at least 20 minutes of technically satisfactory recording. ${ }^{4}$ Whereas International League Against Epilepsy (ILAE) recommends at least 30 minutes of artifact free recording. ${ }^{5}$ Unfortunately, sensitivity of EEG is quite low ranging from 29$55 \% .{ }^{6}$ However, it has been observed that serial EEG recordings increase the diagnostic yield of EEG. ${ }^{7}$ This 
might not be possible for patients in LMIC (low to middle income countries) to visit hospital for repeat studies as they come from far off areas or have to miss their one day salary due to absence from work. Therefore, it seems logical that longer periods of recording should be considered to increase the yield of a single EEG recording to detect abnormalities. In low resource settings like Pakistan where most of the population lives in rural areas with only limited access to neurological services, prolonged EEG recording might be more practical as compared to serial EEGs, and other more expensive options like inpatient video EEG monitoring or ambulatory EEGs. Due to these reasons, this study was conducted to find out the yield of extended or prolonged EEG as compared to standard EEG of 30 minutes duration. It is the first study done in Pakistan that compares the yield of routine with prolonged EEG recording.

\section{METHODOLOGY}

It was a comparative prospective study conducted at Pak Emirates Military Hospital, Rawalpindi from October 2019 to August 2020. It is a tertiary care hospital that covers an area of approximately 20,000 $\mathrm{km}^{2}$ and a population of about 30 million, including northern Punjab, Kashmir, and eastern part of Khyber Pakhtunkhwa province.

The primary aim of the study was to determine the increase in diagnostic yield of EEG by extending the duration of outdoor EEG recording beyond $30 \mathrm{~min}$. The secondary aim was to estimate the yield of EEG in suspected epilepsy patients in addition to determining the time to first epileptiform discharge in both generalized and focal epilepsies.

The WHO sample size calculator was used for estimating the sample size. Values were used from the study by Burkholder et al, ${ }^{8}$ In which, out of the total 518 seizure-specific adult participants, 142 had early IEDs, while 32 patients had late IEDs. These were $36.25 \%$ and $7.66 \%$ of patients for early and late IEDs. In order to test a two-sided hypothesis for two population proportions, with the level of significance at $2 \%$, the power of test at $95 \%$, one anticipated population proportion at 0.2741 and the second anticipated population proportion at 0.0618 , a sample size of 78 participants was estimated ${ }^{8}$. Non-probability consecutive sampling technique was used to select patients for the study.

Inclusion Criteria: The suspected but unconfirmed cases of epilepsy with age more than two years were enrolled for the study.
Exclusion Criteria: All the patients with history suggestive of non-epileptic disorders were excluded.

EEGs were recorded for a minimum duration of 60 minutes. Out of these 55 EEGs were excluded either due to technical errors or artifacts. Thus, 309 patients were included for final analysis. Study design was approved by Institutional Review Board of our hospital (ERC no. A/28/162/EC). Informed consent was obtained in all cases from the patient or from parent/ guardian in case of a minor (age $<18$ years). Age, sex and use of antiepileptic drugs (AED) at the time of recording were noted. EEG was recorded using the international 10-20 system for electrode placement including $\mathrm{Fz}$ and $\mathrm{Oz}$ electrodes. Neurowerk EEG machine model no.17-GWA-1081 was used to record EEGs. Standard time duration for outpatient routine EEGs was taken as 30 minutes according to the recommendations by International League against Epilepsy. A mark was placed at 30 minutes for neurologist to identify the completion of routine EEG. Recording was further extended to a minimum duration of 60 minutes according to criteria for prolonged EEG recording. ${ }^{8}$ Maximum duration of the recording was 187 minutes.

Time of the appearance of first IED or ictal discharge (in case of an epileptic event) was recorded. IED was defined according to international criteria as generalized spike and wave, focal spike and wave, sharp and slow wave or temporal intermittent delta activity ${ }^{9}$. Interictal epileptiform discharges were classified as "Early" or "Late" and as "Focal" or "generalized" for analytic purposes. All discharges appearing within first 30 minutes were considered "Early" whereas those appearing later than 30 minutes were considered "Late". All EEGs were reviewed by two classified neurologists independently. Both relative and absolute increase in diagnostic yield by extending the recording beyond 30 minutes was calculated. Increase in diagnostic yield of $10 \%$ was considered significant.

SPSS-20 was used for statistical analysis. Chi Square goodness of fit test was applied for freq-uency distribution of early versus late discharges in patients. Independent sample t-test was applied for comparison of mean time of discharge between early and late, focal and generalized discharges respectively. Chi-square test was used for frequency distribution of the timing of discharge as per type of discharges. Odds of having focal discharges appearing late in comparison to that of generalized discharges was calculated. The $p$-value of $\leq 0.05$ was considered to be statistically significant. 


\section{RESULTS}

A total of 364 patients underwent outpatient prolonged EEG recording from October 2019 to September 2020. Out of these 55 EEGS were excluded either due to inadequate recording time or because of technical errors. Final analysis included a total of 309 patients out of which $40(12.9 \%)$ were children $<12$ years of age, $76(24.6 \%)$ patients were females whereas remainder
Late discharges were found to occur $39.14 \pm 3.28$ minutes later than early discharges $(p<0.001$; Table-I). There was no significant difference in the mean timing of focal and generalized discharges $(8.60 \pm 5.45 \mathrm{minu}-$ tes; $p \pm 0.125)$. In addition, there was no significant difference in the mean timing of discharges between male and female patients $(7.94 \pm 6.32$ minutes; $p=0.022)$, as shown in Table-II.

Table-I: Comparison of mean time of discharge between groups of different variables $(n=48)$.

\begin{tabular}{|c|c|c|c|c|c|}
\hline \multicolumn{2}{|l|}{ Variables } & $\begin{array}{c}\text { Mean Time of } \\
\text { Discharge (minutes) }\end{array}$ & $\begin{array}{c}\text { Mean Difference in } \\
\text { Time of Discharge } \\
\text { (minutes) }\end{array}$ & $\begin{array}{l}95 \% \text { Confidence Intervals of } \\
\text { Mean Difference in Time of } \\
\text { Discharge (minutes }\end{array}$ & $p$-value \\
\hline \multirow{2}{*}{ Period of Discharge } & Early & $5.94 \pm 6.11$ & \multirow{2}{*}{$-39.14 \pm 3.28$} & \multirow{2}{*}{$(-45.75,32.53)$} & \multirow{2}{*}{$<0.001$} \\
\hline & Late & $45.08 \pm 16.95$ & & & \\
\hline \multirow{2}{*}{ Type of Discharge } & Focal & $22.00 \pm 14.94$ & \multirow{2}{*}{$8.60 \pm 5.45$} & \multirow{2}{*}{$(-2.52,19.72)$} & \multirow{2}{*}{0.125} \\
\hline & Generalized & $13.40 \pm 20.92$ & & & \\
\hline \multirow{2}{*}{ Gender } & Male & $12.59 \pm 20.53$ & \multirow{2}{*}{$-7.94 \pm 6.32$} & \multirow{2}{*}{$(-20.91,5.03)$} & \multirow{2}{*}{0.220} \\
\hline & Female & $20.53 \pm 24.57$ & & & \\
\hline
\end{tabular}

$233(75.4 \%)$ patients were male. Mean age of our patients was $22.3 \pm 6.16$ years with range of $6-53$ years. A total of $187(60.5 \%)$ patients were already taking at least one antiepileptic drug.

Mean duration of EEG recording was $147.4 \pm$ 35.07 minutes with a median of $160 \mathrm{~min}$. The time range was from $60-187 \mathrm{~min}$. Interictal discharges (IED) were seen in $48(15.6 \%)$ EEGs. Out of these, 36 (11.7\%) interictal discharges appeared early/within first 30 minutes in $36(11.7 \%)$ recordings ( $p$-value 0.001$)$. Whereas in $12(3.9 \%)$ recordings, discharges appeared late/ after first 30 minutes. Mean time of IED appearance was $14.7 \pm 19.09$ minutes (median 6 minutes). IEDs in $46(95.8 \%)$ of the cases appeared within 60 minutes. In only two patients, discharges were seen later than that (at minute 71 and 87). Thus, an increase of $33.3 \%$ in diagnostic yield was observed by increasing the recording time beyond 30 minutes. That means an absolute increase of $3.6 \%$ in overall yield (Figure).

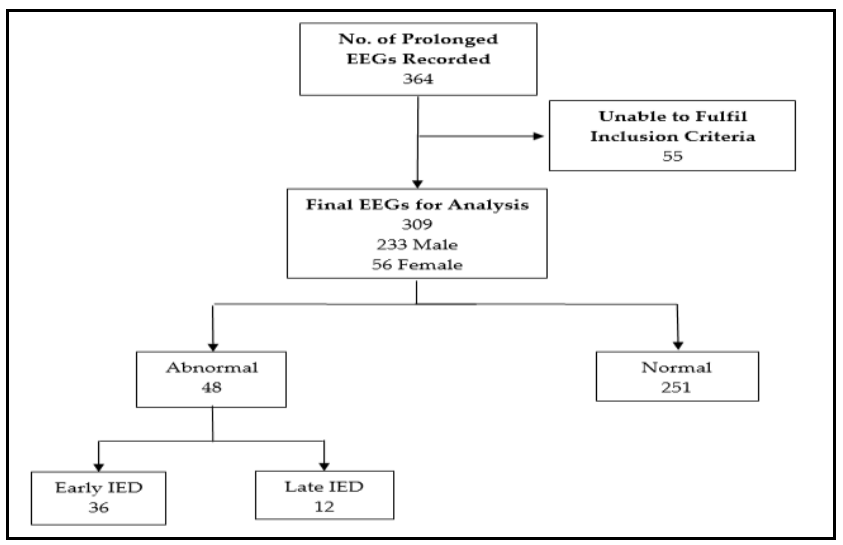

Figure: Study profile-organogram.
Out of 48 EEGs with IED, 35 recordings showed generalized discharges whereas 13 showed focal discharges. Both kinds of discharges increased by $20 \%$ and $38.6 \%$ respectively with extended duration of recording. Focal discharges were at 0.40 odds of having early discharges, as compared to generalized discharges. i.e. odds ratio (focal discharge/generalized discharge $)=0.40(95 \%$ CI 0.10, 1.61) (Table-II).

Table-II: Timing wise frequency distribution of type of discharge.

\begin{tabular}{l|c|c|c|c}
\hline & $\begin{array}{c}\text { Focal } \\
\text { Discharge }\end{array}$ & $\begin{array}{c}\text { Generalized } \\
\text { Discharge }\end{array}$ & $\begin{array}{c}\text { Odds Ratio } \\
(\mathbf{9 5 \%} \text { CI) }\end{array}$ & $\begin{array}{c}p \text { - } \\
\text { value }\end{array}$ \\
\hline $\begin{array}{l}\text { Early } \\
\text { Discharge }\end{array}$ & $8(61.5 \%)$ & $28(80 \%)$ & 0.40 & 0.189 \\
\cline { 1 - 2 } $\begin{array}{l}\text { Late } \\
\text { Discharge }\end{array}$ & $5(38.5 \%)$ & $7(20 \%)$ & $(0.10-1.61$ & \\
\multicolumn{2}{l|l}{ CI=Confidence Intervals; $n=48}$.
\end{tabular}

Further details are given in Table-I and II. There was a significant increase in the number of patients who slept during the prolonged EEG recording. Out of 309 patients, $289(93.5 \%)$ went into stage 1 or 2 sleep during prolonged EEG recording. Whereas only 85 $(27.5 \%)$ patients slept during standard 30 minutes EEG recording, most of these being children.

\section{DISCUSSION}

Electroencephalography (EEG) is a non-invasive and relatively inexpensive method for assessing neurophysiological function of human brain. It measures the electrical activity of a large number of synchronously firing neurons in the brain with electrodes placed on the scalp. ${ }^{10}$ EEG is widely used in diagnosis and management of epilepsy. ILAE defines epilepsy as a disease of brain with either two or more unprovoked seizures $>24$ hours apart or one unprovoked seizure 
and at least $60 \%$ probability of seizure recurrence within the next 10 years. ${ }^{11}$ There are very few reliable biomarkers to decide on this $60 \%$. These include clinical settings, family history and EEG. ${ }^{12}$ According to American Academy of neurology chance of having a second seizure after an unprovoked seizure in an adult is $47 \%$ if EEG is normal whereas it increases to $77 \%$ if the EEG shows some epileptiform abnormality. ${ }^{7}$ Thus, a routine EEG remains a recommended test in investigation of unprovoked seizures for both children and adults.

EEG not only predicts risk of future seizures but also provides diagnostic certainty, seizure classification and helps in management and predicting prognosis. In addition, EEG is the basic tool in localizing the epileptogenic focus in focal epilepsies. However, unfortunately, EEG is not a very sensitive test and has many intrinsic and extrinsic limitations. A single standard EEG recording of 30 minute duration in an otherwise unselected patients with proven epilepsy, has yield of only $29-55 \% .^{6}$ It has been observed that the yield can be increased by doing serial EEGs as there is incremental yield of $49.1 \%$ with second and $67.6 \%$ with third EEG. ${ }^{7}$ In addition many provocation methods are also used to increase the EEG yield, including hyperventilation, intermittent photic stimulation, sleep deprivation and sleep recordings.13,14 Thus, although sensitivity of a single EEG is low, it can be increased to $>90 \%$ by repeated studies. ${ }^{6}$ Inpatient video recordings done are done in Epilepsy monitoring units to record ictal and interictal discharges in difficult cases. ${ }^{15} \mathrm{Am}-$ bulatory EEG is another alternative when routine EEGs do not show any epileptiform activity and diagnosis is in doubt. ${ }^{16}$ In a resource poor country like Pakistan where neurology is still evolving gradually whereas neurophysiologic services are still in infancy, there is lack not only of infrastructure but also of trained neurophysiologist to read EEG. Hence, repeated studies may not be possible when patients belongs to remote area and frequents visits not feasible due to administrative issues. ${ }^{17}$

A total of 309 EEGs with a mean duration of 147 minutes were included in this study. An increase of $33 \%$ in relative yield was observed by extending the time of recording beyond 30 minutes. This translated into 3.6\% absolute increase in IED across all patients. Overall yield of epileptiform discharges in suspected epilepsy patients turned out to be $15.5 \%$. An important observation was that whereas routine 20-30 minute recording including the activation procedures usually does not allow time for sleep, most of the patients went into stage 1 and 2 sleep during prolonged monitoring (93\% vs. $27.5 \%$ ). This seems to be an important factor in increasing the yield because sleep has been proved to be the most powerful activation procedure in most subjects.

This study has many important practical implications. In developing countries like Pakistan where neurology services are limited 18,19 , and $67 \%$ of the population lives in rural areas, ${ }^{20}$ repeated hospital visits for serial EEGs are often not possible. Similarly, inpatient prolonged video recordings also very expensive and requires extensive resources. In this situation doing outdoor prolonged recording is a viable option, that saves repeated visits, hospital admissions and expenses of inpatient video recording or ambulatory EEG.

Many past studies have also shown increased diagnostic yield with prolonged duration of EEG recording. Most remarkable of these was a large single centre study conducted by Burkholder et $a l, 8$ in which analysis of 1803 EEGs of 60 minutes duration was done to compare the yield of IED and clinical events within first 30 minutes versus those appearing later. Results showed that an additional 17.5\% of IED were recorded after initial 30 minutes. Both epileptic and non-epileptic events were captured frequently after initial 30 minutes. ${ }^{8}$

Another large study was done in Taiwan by Lee $e t$ $a l$, to analyze the latency to first IED or clinical event. The results showed that $64 \%$ of the epileptiform discharges appeared within first 30 minutes and the detection rate for IED was higher for 3 hours EEG recording as compared to routine 20 minutes recording. The mean duration to first epileptiform activity turned out to be 22.1 minutes in case of generalized epilepsy and 30.6 minutes for focal seizures in this study. ${ }^{21}$

Similar results were corroborated by Losey et al, who evaluated the latency of IED in 172 extended EEG recordings with a minimum duration of 60 minutes. In this study, $53 \%$ of the discharges appeared within 20 minutes, while $47 \%$ of the discharges appeared afterwards. Mean time to first epileptiform discharge was 32.8 minutes. An important observation was that there was a longer time to the first IED in temporal epileptiform discharges compared with generalized discharges..$^{22}$

\section{CONCLUSION}

There was higher yield of interictal epileptiform discharges with prolonged EEG recording as compared to standard 30 minute recording. This supports extending the duration of EEG recording beyond 30 minutes if some abnormality does not appear within that timeframe. It is a practical 
option in low resource settings where inpatient video EEG or ambulatory EEG are not available.

\section{LIMITATION OF STUDY}

This study had a few important limitations. First of all, it was a single centre study; secondly the study mostly included adults. There were only 40 (12.9\%) children younger than 12 years of age.

\section{Conflict of Interest: None.}

\section{Authors' Contribution}

SS: Direct contribution, WA: Direct contribution, IA: Direct contribution, SA: Direct contribution, JL: Direct contribution.

\section{AH: Direct contribution.}

\section{REFERENCES}

1. Fiest KM, Sauro KM, Wiebe S, Patten SB, Kwon CS, Dykeman J, et al. Prevalence and incidence of epilepsy: a systematic review and meta-analysis of international studies. Neurol 2017; 88(3): 296-303.

2. Beghi E. The Epidemiology of Epilepsy. Neuroepidemiol 2020; 54(2): 185-191.

3. Olejniczak P. Neurophysiologic basis of EEG. J Clin Neurophysiol 2006; 23(3): 186-189.

4. Sinha SR, Sullivan LR, Sabau D, Orta DS, Dombrowski KE, Halford JJ, et al. American clinical neurophysiology society guideline 1: minimum technical requirements for performing clinical electroencephalography. Neurod J 2016; 56(4): 235-244.

5. Flink R, Pedersen B, Guekht AB, Malmgren K, Michelucci R, Neville B, et al. Guidelines for the use of EEG methodology in the diagnosis of epilepsy: International League Against Epilepsy: Commission Report Commission on European Affairs: Subcommission on European Guidelines. Acta Neurol Scand 2002; 106(1): 1-7.

6. Pillai J, Sperling MR. Interictal EEG and the diagnosis of epilepsy. Epilep 2006; 47(1): 14-22.

7. Debicki DB. Electroencephalography after a single unprovoked seizure. Seizure 2017; 49(2): 69-73.

8. Burkholder DB, Britton JW, Rajasekaran V, Fabris RR, Cherian PJ, Kelly-Williams KM, et al. Routine vs extended outpatient EEG for the detection of interictalepileptiform discharges. Neurol 2016; 86(16): 1524-1530.
9. Benbadis SR, Beniczky S, Bertram E. The role of EEG in patients with suspected epilepsy. Epileptic Disord 2020; 22(2): 143-55.

10. Light GA, Williams LE, Minow F, Sprock J, Rissling A. Electroencephalography (EEG) and eventrelated potentials (ERPs) with human participants. Curr Protoc 2010; 52(1): 6-25.

11. Fisher RS. Redefining epilepsy. Curr Opin Neurol 2015; 28(2): 130-135.

12. Stroink H, Brouwer OF, Arts WF, Geerts AT, Peters AB, van. The first unprovoked, untreated seizure in childhood: a hospital based study of the accuracy of the diagnosis, rate of recurrence, and long term outcome after recurrence. Dutch study of epilepsy in childhood. J Neurol Neuros Psychiat 1998; 64(5): 595-600.

13. Leach JP, Stephen LJ, Salveta C, Brodie MJ. Which electroencephalography (EEG) for epilepsy? The relative usefulness of different EEG protocols in patients with possible epilepsy. J Neurol, Neurosurg Psychiat 2006; 77(9): 1040-1042.

14. Meritam P, Gardella E, Alving J, Terney D, Hribljan MC, Beniczky S. Diagnostic yield of standard-wake and sleep EEG recordings. Clin Neurophysiol 2018; 129(4): 713-716.

15. Alving J, Beniczky S. Diagnostic usefulness and duration of the inpatient long-term video-EEG monitoring: findings in patients extensively investigated before the monitoring. Seizure 2009; 18(7): 470-473.

16. Otárula KA, Mikhaeil-Demo Y, Bachman EM, Balaguera P, Schuele S. Automated seizure detection accuracy for ambulatory EEG recordings. Neurol 2019; 92(14): e1540-e1546.

17. Ahmad I, Rathore FA. Current situation and future recommendations for neurophysiology services in Pakistan. Pak J Neurol Sci 2019; 14(1): 1-3.

18. Awan T, Ahmad A, Javed A, Wasay M, Babar Khan M, Awan H. Neurological health profile in pakistan-A health systems based needs assessment. Pak J Neurol Sci 2016; 11(4): 43-56.

19. Wasay M. Neurology in Pakistan: Growing burden, low on priority, and a hope to keep alive. Neurol 2013; 80(6): 581-582.

20. Government of Pakistan, Economic survey of Pakistan, Islamabad, Ministry of Finance; 2016-17, [Internet] Available at: https://www.finance.gov.pk/survey/chapters_17/Pakistan_ES _2016_17_pdf.pdf.(Accessed on Sep 25,2020)

21. Lee $\mathrm{CH}$, Lim SN. Duration of electroencephalo-graphic recordings in patients with epilepsy. Seizure 2013; 22(6): 438-442.

22. Losey, Travis E. Uber-Zak, Lori: time to first interictal epilepti form discharge in extended recording EEGs, J Clin Neurophysiol 2008; 25(6): 357-360. 